\title{
O ESTUDANTE DE ENFERMAGEM DO SEXO MASCULINO: UM PROBLEMA PARA O ENSINO DE ENFERMAGEM OBSTETRICA?
}

\author{
Maria Alice Tsunechiro *
}

TSUNECHIRO, M.A. O estudante de enfermagem do sexo masculino: um problema para o ensino de enfermagem obstétrica? Rev. Esc. Enf. USP, São Paulo, 14 (3): 281-285, 1980.

A autora faz consideracofes sobre o ensino de enfermagem obstétrica a estudantes do sexo masculino $e$ relata o ensino dessa disciplina a esses estudantes na Escola de Enfermagem da USP.

Para o ingresso nos cursos de graduação em enfermagem não existe discriminaçăo de sexo; assim sendo, o ensino das disciplinas de enfermagem deve ser o mesmo para os estudantes de ambos os sexos.

No entanto, nem todos os estudantes do sexo masculino da EEUSP tiveram experiência teórico-prática em enfermagem obstétrica. Os hospitais utilizados para o ensino de campo desta disciplina não permitiam o estágio de estudantes masculinos; alegavam, para fundamentar a recusa, que as "pacientes" (gestantes, parturientes e puérperas) não aceitam ser assistidas pelos mesmos e que a prática de campo em enfermagem obstétrica não é necessária para homens. Assim, na EEUSP, até há alguns anos, a prática de campo em enfermagem obstétrica para estudantes masculinos era substituida por estágio em clínica urológica ou ortopédica.

PELÁ \& IMPERATRIZ 13 realizaram, por meio de questionário, um levantamento sobre o ensino de enfermagem obstétrica para estudantes masculinos, nas escolas de enfermagem do Brasil; constataram que 76,2\% dos cursos de enfermagem que recebiam estudantes do sexo masculino proporcionavam o ensino teóricoprático em enfermagem obstétrica e 23,8\% apenas o ensino teórico. Mencionam, entre as justificativas mais citadas para a omissáo do ensino teórico-prático de enfermagem obstétrica as seguintes: "o diretor da maternidade ñ̃o aceita estudantes do sexo masculino" e "esses estudantes não são aceitos pelas pacientes". As autoras consideram que os motivos apresentados estáo ligados a preconceitos e a uma "tradição de ensino de enfermagem onde somente mulheres podem prestar cuidados no ciclo grávido-puerperal".

A influência da tradição e dos preconceitos na atitude de profissionais e de leigos em relação à atuação de homens na assistência à mulher no ciclo grávido-puerperal tem raízes históricas 6,7 . JORGE ${ }^{9}$, em estudo sobre a evolução da legislação federal do ensino e do exercício profissional da obstetriz no Brasil desde o período colonial ressalta que, o "exercício da arte de partejar" era exclusivo das mulheres; neste estudo verifica-se que a denominação do profissional está redigido sempre no feminino, o que especifica esta atividade como exclusivamente da mulher.

Professor Assistente das disciplinas Enfermagem Obstétrica e Neonatal e Enfermagem Ginecológica da EEUSP. 
Este monopólio profissional das mulheres tem criado polêmica entre diferentes autores, principalmente quando se refere à formação de profissionais do sexo masculino $1,2,3,5,8,10,12,13$. Do mesmo modo, esta polêmica é observada, embora em menor intensidade, quando se refere à formação do enfermeiro geral.

A questão é: se a experiência prática em todas as áreas de enfermagem é essencial para o estudante de enfermagem do sexo feminino, por que não para o estudante de enfermagem do sexo masculino? se bombeiros e policiais recebem noçóes práticas elementares de assisténcia materna porque ao enfermeiro, um profissional de saúde, é negado ou omitido o ensino prático em enfermagem obstétrica?

$\mathrm{Na}$ Inglaterra, o "Royal College of Midwives", apesar de contrário à formação de "male midwives", reconhece a necessidade do ensino de enfermagem obstétrica ao estudante masculino a fim de torná-lo capaz de prestar os cuidados exigidos numa emergência obstétrica ${ }^{15}$.

BANKS $^{1}$, do País de Gales, é de opinião que o ensino de enfermagem a estudantes masculinos seja apenas o suficiente para o atendimento em situaçőes de emergência obstétrica como acontece com motoristas de ambulância e policiais. A autora relata ainda que: a gestante, parturiente ou puérpera, permite apenas que o obstetra e a obstetriz façam o exame em seu corpo; os procedimentos de assistência obstétrica são tarefas íntimas que devem ser executadas por mulheres; $e$, o homem normal é despertado sexualmente pela visão de um corpo feminino exposto o que é embaraçoso.

Em um artigo do "The Canadian Nurse" 16, verifica-se que, nas escolas de enfermagem do Canadá, nem todos os estudantes masculinos têm a experiência teóricoprática em enfermagem obstétrica. Entretanto, em hospitais onde os estudantes masculinos prestam cuidados de enfermagem obstétrica, as mulheres mostraram-se satisfeitas e declararam que os procedimentos de enfermagem não sáo mais embaraçosos que os exames médicos. Por isso é enfatizada a necessidade de se proporcionar experiência clínica geral em todas as áreas de enfermagem aos estudantes do sexo masculino uma vez que admitem homens nas escolas de enfermagem.

McCARRICK 11 descreve a experiência de uma escola de enfermagem da Escócia que oferece o ensino prático em enfermagem obstétrica aos estudantes do sexo masculino; relata que inicialmente houve reserva por parte de algumas pessoas da equipe de enfermagem e das pacientes, porém, ressalta que a atitude e a personalidade dos estudantes foram os fatores mais importantes para sua aceitação.

$\mathrm{Na}$ bibliografia consultada encontramos depoimentos de alguns enfermeiros e estudantes de enfermagem do sexo masculino da Inglaterra que tiveram experiência prática em enfermagem obstétrica.

BEILBY 2 , enfermeiro diplomado na Inglaterra, para poder trabalhar em hospital da Califómia (EUA) precisaria ter conhecimentos de obstetrícia; para tanto, submeteu-se à prática em enfermagem obstétrica por oito semanas. Durante o treinamento, ficou surpreso pelo fato das mães terem aceito a sua presença e a assistência prestada por enfermeiro e relata que, em nenhum momento, sentiu-se sexualmente estimulado pela visão do corpo feminino exposto e do contato com este como declara BANKSI. Acredita que o seu comportamento o seu relacionamento pessoal, o apoio e a ajuda de todo o pessoal foram fundamentais para o sucesso de sua presença masculina na matemidade. 
Comenta CHALMERS ${ }^{4}$, estudante de enfermagem de Londres, que a surpresa com sua presença na maternidade foi maior entre o pessoal da clínica do que entre as pacientes; afirma também que "a mulher só fica encabulada se você se encabular" e reconhece que, após o estágio em obstetrícia, sente-se um enfermeiro mais eficiente. Isto porque, antes, se irritava com o fato de acreditar que o motorista de ambulância tinha mais conhecimentos para atuar em situações de emergência obstétrica do que ele.

HALL 8 , enfermeiro inglês, descreve seu treinamento em enfermagem obstétrica e relata a surpresa e o alívio que sentiu com a quase ausência de constrangimento por parte das senhoras durante as palpações abdominais ou quando presenciava exames obstétricos. $\mathrm{O}$ autor sempre lamentou não ter podido freqüentar o curso de obstetrícia durante o tempo do estudante, pois o sistema de ensino não o permitia.

Por sua vez, na Inglaterra, SWEET 14 preocupada com a presença de homens na obstetrícia, fez um levantamento, por meio de questionário, sobre a reação das pacientes à assistência obstétrica prestada por homens. Concluiu que as mulheres não estão completamente preparadas para aceitar homens na enfermagem obstétrica. As questర̃es que receberam maior aceitação foram referentes ao cuidado pré-natal e ao recém-nascido e as menos aceitas foram aquelas que se referiam aos cuidados pessoais mais íntimos.

Em nosso meio, conhecemos apenas o trabalho de PELÁ \& IMPERATRIZ ${ }^{13}$ que trata deste assunto. Em uma de suas conclusð̃es as autoras afirmam que "os profissionais de enfermagem (enfermeiros e auxiliares de entermagem) inquiridos ressal taram a necessidade dos conhecimentos adquiridos nessa disciplina".

Consultando enfermeiras e obstetrizes (ou enfermeiras obstétricas) tanto de campo como docente, verificamos que o assunto é controvertido não havendo relação com o tempo de vivência profissional nem com a idade das mesmas. Parece-nos que o fator que influi fundamentalmente as opiniбes é a formação pessoal.

Há já alguns anos, na EEUSP, estamos orientando estudantes do sexo masculino em enfermagem obstétrica do tronco profissional comum. No passado, a disciplina oferecia apenas o ensino teórico e o teórico-prático era proporcionado apenas em berçário.

Aproximadamente há oito anos, os estudantes começaram a estagiar na unidade de pré-natal e, logo a seguir, no centro obstétrico.

Com o passar dos anos e dos grupos de alunos, toda a prática de campo da disciplina enfermagem obstétrica foi proporcionada ao estudante do sexo masculino, inclusive o estágio em puerpério.

Nossa experiência tem mostrado que um dos fatores que influi positivamente para o desenvolvimento do ensino teórico-prático em enfermagem obstétrica aos estudantes masculinos é a atitude de todo o pessoal envolvido no processo: o próprio estudante, a docente, as colegas de classe, o pessoal médico e os funcionários do hospital ou matemidade. Outro fator que favorece o ensino a este estudante é que no campo de estágio utilizado por nós, é comum a presença de estudantes de medicina de ambos os sexos.

Além disso, náo temos observado recusa por parte das mulheres assistidas em qualquer fase do ciclo grávido-perperal aos cuidados obstétricos prestados pelos estu- 
dantes masculinos. Observamos ocasionalmente certo constrangimento que tanto pode ser por parte das "pacientes" como dos estudantes ou de ambos. Entretanto, este tipo de constrangimento é observado também quando os cuidados sáo prestados por enfermeiras, fato natural, pois trata-se de pessoas com padrбes culturais e morais dos mais variados. Cremos que esta situação emocional não deve ser considerada como fator para impedir a experiência prática de estudantes do sexo masculino em enfermagem obstétrica.

Durante o estágio nas unidades de pré-natal, de centro obstétrico, de puerpério e de berçário, procuramos proporcionar oportunidades semelhantes de aprendizagem aos estudantes de ambos os sexos. $O$ estudante desenvolve a maioria das atividades assistenciais com uma colega ou com uma docente; porém, nas atividades consideradas mais embaraçosas, como por exemplo o curativo da episiorrafia, o estudante observa o desempenho da colega ou apenas a auxilia na sua execução.

Somos de opinião que as justificativas geralmente apresentadas para omitir o ensino teórico-prático em enfermagem obstétrica ao estudante masculino decorrem de crenças difundidas entre alguns profissionais tanto de campo como ligados ao ensino.

E preciso reconhecer que o estudante masculino tem sentimentos, e, ao omitirmos a referida experiência teórico-prática, estamos levando-o a sentir-se frustrado, rejeitado e quase sempre criando sentimento de revolta. Aliás, este é um fato observado por nós, em tempos passados.

Acreditamos ser possivel que a docente analise cada situação, e, com o estudante, tente encontrar o melhor caminho para lhe oferecer as mesmas oportunidades de aprendizagem que têm as estudantes do sexo feminino durante o programa do tronco profissional comum.

Quanto à justificativa citada por PELȦ \& IMPERATRIZ 13 “estes estudantes não são aceitos pelas pacientes", houve uma tentativa de nossa parte de elaborar um trabalho de pesquisa para conhecer se existe esta rejeição; porém, no teste-piloto esbarramos com um obstáculo - o desconhecimento da profissão de enfermeiro por parte das mulheres entrevistadas. Por este motivo, antes de aplicar o questionário houve a necessidade de explicar a todas as mulheres o que é enfermagem e o que é enfermeiro. Porém, não encontramos meios que nos permitisse avaliar a compreensão desta explicação por parte da mulher entrevistada. Nesta pesquisa, a população era composta de mulheres de condiçס̋es sócio-econômicas desfavorecidas, assistidas em hospitais-escola e assistenciais onde são desenvolvidos os estágios em enfermagem obstétrica dos estudantes da EEUSP.

Além disso, houve falhas no questionário e após vários ensaios em elaborar um instrumento de coleta de dados adequado, suspendemos o referido trabalho de pesquisa.

Em vista de nossa tentativa frustrada, sugerimos que outras docentes ou enfermeiras de campo continuem na investigação do grau de aceitação ou rejeição por parte das mulheres em relação aos cuidados obstétricos prestados pelo estudante masculino.

NOTA

A autora agradece à Dra. Wanda Escobar da Silva Freddi pela ajuda recebida na realização deste trabalho. 
TSUNECHIRO, M.A. Male nursing students: a problem for the teaching of Obstetrical Nursing?

Rev. Esc. Enf. USP, São Paulo, 14 (3): 281-285, 1980.

The author presents a revision of the literature on the teaching of Obstetrical Nursing to male nursing students and describes the teaching of this subject at the University of Säo Paulo School of Nursing.

\section{REFERENCIAS BIBLIOGRÁFICAS}

1. BANKS, P. Intimate duties of the midwife. Midwives Chron., London, 88 (1044): 15, Jan. 1975.

2. BEILBY, B.G. A place for the male midwife. Midwives Chron., London, 90 (1079): 295-7, Dec. 1977.

3. BLENKIN, T. Male midwives - a feasible prospect? Midwives Chron., London, 88 (1049): 191 , June, 1975.

4. CHALMERS, K. Introduction to obstetrics for male nurses. Midwivwes Chron., London, 90 (1068): 3-4, Jan. 1977.

5. CLAY, T. Male midwives: a male nurse's point of view. Midwife Health Visit., London, 10:79, Apr. 1974.

6. DICKER, K. Toward sexual equality. Nurs Mirror, London, 144 (20): 1, May. 1977.

7. EBERLE, A. Männliche Hebamme? Med. Klin, München, 71 (2): 70-6, 1976.

8. HALL, M. Unforgetable experience. Midwives Chron, London, 90 (1068): 4-5, Jan. 1977.

9. JORGE, D.R. Evoluçāo da legislação federal do ensino e do exercício profissional da obstetriz (parteira) no Brasil. São Paulo, 1976. (Tese Docente Livre - Escola de Enfermagem Ana Neri da Universidade Federal do Rio de Janeiro).

10. MALE midwives: a midwife's point of view. Midwife Health Visit., London, 10:44-5, Feb. 1974.

11. McCARRICK, H. Men in midwifery. Nurs. Times, London, 70 (7): 24-4, , Feb. 1974.

12. MEN mid wives? Nurs. J. India, New Delhi, 65 (9):236, Sept. 1974.

13. PELÁ, N.T.R. \& IMPERATRIZ, D.M. O ensino de enfermagem obstétrica para estudantes masculinos. Rev. Bras. Enf., Rio de Janeiro, 25 (5): 105-14, out. dez. 1972.

14. SWEET, B.R. Patient's reactions to male midwives. Nurs Times, London, $70(42): 1619$, Oct. 1974.

15. THE ROYAL COLLEGE OF MIDWIVES comments on: equal opportunities for men and women. Midwives Chron., London, 87 (1032):6-7, Jan. 1974.

16. WHY not obstetric nursing for male students. Can. Nurse, Ottawa, 62 (10): 40-1, Oct. 1966. 